\title{
Molecular cloning and gene expression analysis of cystatin C-like proteins in spinyhead croaker Collichthys lucidus
}

\author{
W. Song, K.J. Jiang, F.Y. Zhang, M. Zhao and L.B. Ma \\ Key Laboratory of East China Sea \& Oceanic Fishery Resources Exploitation and \\ Utilization, Ministry of Agriculture, East China Sea Fisheries Research Institute, \\ Chinese Academy of Fishery Sciences, Shanghai, China \\ Corresponding authors: K.J. Jiang / L.B. Ma \\ E-mail: jiangkj@ecsf.ac.cn / malingbo@vip.sina.com \\ Genet. Mol. Res. 15 (1): gmr.15017417 \\ Received August 11, 2015 \\ Accepted November 16, 2015 \\ Published March 24, 2016 \\ DOI http://dx.doi.org/10.4238/gmr.15017417
}

\begin{abstract}
Cystatins are natural tight-binding reversible inhibitors of cysteine proteases. In this study, a cDNA library was constructed from Collichthys lucidus using the SMART technique. A complete cDNA sequence with high identity to the conserved sequence of the cystatin $\mathrm{C}$ gene was cloned from the library using EST analysis and rapid amplification of cDNA ends (RACE), then subjected to further investigation. The full-length cDNA of cystatin C from C. lucidus (Clcys) was 699 bp long, including a 5 '-terminal untranslated region (5'-UTR) of $52 \mathrm{bp}$, a 3'-UTR of $290 \mathrm{bp}$, and an open-reading frame of $357 \mathrm{bp}$. The gene encoded a polypeptide of 118 amino acids, constituting a predicted molecular weight of $12.875 \mathrm{kDa}$ and a theoretical isoelectric point of 8.81. The amino acid sequence of Clcys possessed typical features of type II cystatins and had the highest identity with cystatin C of Pseudosciaena crocea (89\%); therefore, it clustered with the cystatin C group in the UPGMA phylogenetic tree. Quantitative realtime reverse transcription analysis revealed that the highest expression was found in the kidney, followed by the liver, heart, and testis, with the lowest expression in muscle. Interestingly, Clcys had relatively low identity
\end{abstract}


with cystatin $\mathrm{C}$ genes from other fish and mammals, and its expression pattern did not possess features of a housekeeping gene. Based on these findings, we suspect that the classification of cystatins in fish is somewhat confusing, and the identification of more cystatin gene sequences is needed before a definite conclusion can be drawn.

Key words: Cystatin C; Collichthys lucidus; Gene cloning; Expression; Quantitative real-time PCR

\section{INTRODUCTION}

Cysteine proteases exist in all living organisms and are involved in various biological and pathological processes, including protein catabolism, antigen processing, inflammation, dystrophy, and metastasis (Vray et al., 2002). The protein from chicken egg white that inhibits cysteine proteinases, known as 'cystatin', has been purified by ovomucin precipitation and affinity chromatography (Anastasi et al., 1983). Following this, other cystatins were found in succession (Grubb et al., 1984; Yamada et al., 2000; Sadaf et al., 2005). Studies on cystatins have commonly focused on tumorigenesis, stabilization of matrix metalloproteinases, glomerular filtration rate (GFR), immunomodulation, and neurodegenerative diseases in mammals (Herget-Rosenthal et al., 2004; Filler et al., 2005; Ochieng and Chaudhuri, 2010; Asnani and Reid, 2015).

Based on the location, molecular weight, and complexity of the peptides, cystatin can be categorized into three major families. Stefins, including stefin $A$ and $B$, also known as cystatins $A$ and $B$, belong to Family 1 . These are unglycosylated cysteine cathepsin inhibitors of $\sim 11 \mathrm{kDa}$, which lack a signal sequence and disulfide bonds, and are generally expressed intracellularly. The lack of cystatin B results in progressive myoclonus epilepsy (Maher et al., 2014). Those belonging to Family 2 have a molecular mass of 13-14 kDa and contain a signal sequence and disulfide bonds at the carboxy terminus (C-terminus) of the molecule. Cystatins C, D, S, SA, and $\mathrm{SN}$ are representative of Family 2, and some members in this family are glycosylated (Ni et al., 1997; Cornwall and Hsia, 2003). Human serum cystatin C has been suggested to be a simple, accurate, and rapid endogenous marker of GFR (Coll et al., 2000; Dharnidharka et al., 2002; Calero-Paniagua et al., 2014). Kininogens are representative of Family 3, and have molecular weights ranging from 88 to $114 \mathrm{kDa}$. These proteins are glycosylated and contain three Family 2 cystatin domains, including two (domains 2 and 3) that have protease-inhibitory activities (Ochieng and Chaudhuri, 2010).

Unlike mammals, studies investigating cystatins in fish have mainly focused on their immune role and their application in food engineering. Many cystatin-like proteins have been characterized, including those from rock bream (Premachandra et al., 2012), Pseudosciaena crocea (Li et al., 2009), Clarias batrachus Linnaeus (Mohindra et al., 2013), chum salmon (Yamashita and Konagaya, 1996), sturgeons (Bai et al., 2002), rainbow trout (Li et al., 1998), and olive flounder (Ahn et al., 2013a,b). Some of these have been shown to respond to bacterial challenge or to be involved in other immune processes (Li et al., 2009; Xiao et al., 2010; Premachandra et al., 2012), while some recombinant cystatins have been shown to have potential use in food engineering, where they may be used to prevent gel weakening by addition to surimi (Nakamura et al., 1998; Kang and Lanier, 2005; Jiang 2006; Li et al., 2007). In addition, cystatin has been identified as a component of carp chorion and is an important compound for preventing polyspermy (Chang et 
al., 1998; Wang and Huang, 2002; Su et al., 2005). In C. batrachus, a novel cystatin-like gene clustering in Family 2 has been cloned and its expression was found to respond to both short and long periods of hypoxia, which suggests that $C$. batrachus cystatin may be involved in tolerance to hypoxia (Mohindra et al., 2013). Taken together, these findings highlight the importance of studies investigating cystatin in fish.

Collichtys lucidus Richardson (Perciformes, Sciaenidae, Collichthys) is a commercially important near-shore species widely distributed in the South China and East China Seas (Cheng et al., 2012). Although great progress has been made in artificial propagation of C. lucidus since 2014, studies on this species have mainly focused on the mitogenome, microsatellites, and auxology (Cheng et al., 2012; Zhao et al., 2015). The aim of the present study was to characterize C. lucidus cystatin C (Clcys) mRNA sequences, analyze one sequence using bioinformatics and to clarify the pattern of tissue expression in adult $C$. lucidus, in an attempt to lay a preliminary foundation for the further study of $C$. lucidus.

\section{MATERIAL AND METHODS}

\section{Construction of a cDNA library and cloning of Clcys cDNA from C. Iucidus}

Healthy fish weighing $35 \pm 5 \mathrm{~g}$ were captured from the East China Sea area near Shanghai, China. Tissues weighing $200 \pm 50 \mathrm{mg}$ for RNA extraction were obtained through vivisection on fishing boats and stored in $1.5 \mathrm{~mL}$ RNA fixer (Bioteke Corporation, Beijing) at $-20^{\circ} \mathrm{C}$. Total RNA was isolated from the liver, gill, heart, muscle, and blood of $C$. lucidus using TRIpure Reagent (Aidlab, Beijing) following the manufacturer protocol. RNA quality and concentrations were determined by agarose gel electrophoresis (Universal Hood II, Bio-Rad Laboratories Inc., Hercules, CA, USA) and spectrophotometry (DU800 Nucleic acid/Protein Analyzer, Beckman Coulter). The RNA was stored at $-80^{\circ} \mathrm{C}$ until use.

A cDNA library was constructed successfully using SMART ${ }^{\mathrm{TM}}$ CDNA Library Construction Kit (TaKaRa, Dalian, China), followed by transformation, screening, and sequencing. Random sequencing was performed after cDNA library construction. All the expressed sequence tags were subjected to BLAST analysis.

A cDNA sequence comprising a Clcys domain was obtained and subjected to further investigation. Next, 3'-rapid amlification of cDNA ends (RACE) was carried out following the manufacturer protocol using the 3'-full RACE Core Set (TaKaRa) to obtain the full-length cDNA sequence. Two gene specific-primers, namely CL-cys-outer (5'-AAGCGTCGAGCTGTTGTT-3', as 3'-RACE amplification outer primer) and CL-cys-inner (5'-TGTCCCAGCGAAGTGTTA-3', as the nest PCR primer) were designed according to the obtained sequence and used for 3'-RACE. PCR followed the manufacturer instructions. The PCR products were checked by $1.0 \%$ agarose gel and purified by the Agarose Gel DNA Purification kit Ver. 2. 0. (TaKaRa Biotechnology), and subsequently cloned into the pMD19-T vector (TaKaRa) for sequencing.

\section{Bioinformatic analysis}

General features of Clcys full-length cDNA were detected by Vector NTI Advance 11.5, and the peptide sequence was deduced and confirmed according to other cystatins using NCBI ORF Finder (available online at http://www.ncbi.nlm.nih.gov/gorf/gorf.html). The biochemical features of 
the deduced protein were calculated with the Expert Protein Analysis System (http://web.expasy. org/). Signal peptide cleavage sites were predicted by SignalP 4.1 Server (http://www.cbs.dtu. $\mathrm{dk} /$ services/SignalP/). Amino acid sequences from various species were obtained from $\mathrm{NCBI}$ GenBank and analyzed using the MEGA software version 5.0. A UPGMA tree was constructed using the MEGA software version 5.0 and the confidence level in the generated tree was obtained using 1000 bootstraps.

\section{Tissue distribution analysis of the mRNA of Clcys in adult $C$. lucidus}

Tissues including the liver, gill, heart, muscle, brain, testis, cholecyst, spleen, blood, and kidney were obtained using the same method described above. Total RNA $(\sim 1 \mu \mathrm{g})$ was extracted and reverse transcribed using a quantitative real-time PCR (qRT-PCR) Kit (Toyobo, Japan) to generate first-strand cDNA. The products were diluted $10 \mathrm{X}$ and stored at $-20^{\circ} \mathrm{C}$ until qRT-PCR analysis.

The qRT-PCR assay was carried out in a detection system (StepOne Plus, Applied Biosystems) and the transcript expression profiles of Clcys in eight different tissues of $C$. lucidus were detected by qRT-PCR using a pair of Clcys-specific primers (CL-cys-RT-F: 5'-ACAATTACGTCATAACCACCAAG-3' and CL-cys-RT-R: 5'-CGTCACCGATATTTCATTCAGC$3^{\prime}$ ), and a pair of $18 \mathrm{~S}$ rRNA primers (18S-RT-F: 5'-GCCTGAATACCGCAGCTAGGAATAA-3' and 18S-RT-R: 5'-TTTCACCTCTAGCGGCACAATACG-3') designed from the 18S rRNA sequence deposited in NCBI GenBank (accession No. JN211725.1) was used as an internal control. Levels of Clcys expression were calculated by the standard curve method. Amplifications were performed on a 96-well plate in a $20-\mu \mathrm{L}$ reaction volume containing $10 \mu \mathrm{L} 2$ X Power SYBR Green PCR Master Mix (TaKaRa, Applied Biosystems), $1.0 \mu \mathrm{L}$ PCR Forward Primer (10 $\mu \mathrm{M}), 1.0 \mu \mathrm{L}$ PCR Reverse Primer (10 $\mu \mathrm{M}), 2.0 \mu \mathrm{L}$ cDNA temple, and $6 \mu \mathrm{L}$ diethylpyrocarbonate-treated water. The reaction process for qRT-PCR was $10 \mathrm{~min}$ at $95^{\circ} \mathrm{C}$, followed by 40 cycles of $95^{\circ} \mathrm{C}$ for $15 \mathrm{~s}$, and $60^{\circ} \mathrm{C}$ for $1 \mathrm{~min}$.

\section{RESULTS AND DISCUSSION}

\section{Cloning of Clcys cDNA}

The full-length cDNA of Clcys was 699 bp long (GenBank accession No. KP771714), containing a 357-bp ORF encoding a protein of 118 amino acids, and the Clcys sequence included a 5'-UTR of $52 \mathrm{bp}$ and a 3'-UTR of $290 \mathrm{bp}$ including a poly(A) tail (Figure 1). The predicted molecular weight of Clcys was $12.875 \mathrm{kDa}$ with an isoelectric point of 8.81. A 21-amino acid signal peptide (amino acid residues 1-21) was found in the N-terminal region, suggesting that Clcys is secreted. In addition, Clcys contains structural features of Family 2 cystatins, including three evolutionally conserved motifs that are known to interact with the active sites of cysteine peptidases: Gly at the N-terminus (Gly25), GIn-X-Val-X-Gly motif (Q69LVAG73), and Pro-Try pair at the C-terminus (P106W107) (Dieckmann et al., 1993; Li et al., 2009). These findings suggest that Clcys may serve as a cysteine protease inhibitor that is involved in physiological processes of $C$. lucidus.

Human cystatin C, a powerful physiological protein inhibitor of cathepsins $B, H$, and L, contains two disulfide bridges (Cys73-Cys83 and Cys97-Cys117), at least one of which is essential for its inhibitory activity (Grubb et al., 1984). However, Cys83 seemed to be deleted in C. lucidus 
and an alternative Cys residue (Cys56 in Clcys) was found, which may cause the first disulfide bond of Clcys to move towards the N-terminus. This has previously been found in P. crocea, and does not appear to have a significant effect on the biological activity of cystatin $C$ of $P$. crocea (Lyccys), since rLyccys produced in Escherichia coli exhibited obvious protease-inhibitory activity and affinity binding to papain with a $\mathrm{K}_{\mathrm{i}}$ of $1.3 \times 10^{-13} \mathrm{M}$, which is in the $\mathrm{pM}-\mathrm{fM}$ range of $\mathrm{K}_{\mathrm{i}}$ determined as it is in mammalian and avian cystatin C (Li et al., 2009).

\begin{tabular}{|c|c|}
\hline & \\
\hline & ATG TGGAAGAT TGTCCTGGCTGT TTT TGCGGCGGT TCTCGCCG TCAGCTOGGCTGGT T TG \\
\hline & 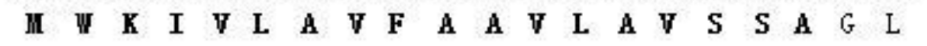 \\
\hline & ATCGGGGGCTTCCAMGACATTGG TGTGAATGATGTAGGGGTGCARAATGOCCTCAMCG OC \\
\hline 24 & $\begin{array}{llllllllllllllllllll}I & G & G & F & Q & D & I & G & V & \mathbb{N} & D & V & G & V & Q & N & A & L & N & A\end{array}$ \\
\hline 181 & GCCGTCG TCCAACACAACAGGGAG AGCAMCGOGATG TG TOCCAGCGAAG TG TTAMGGG TG \\
\hline 14 & 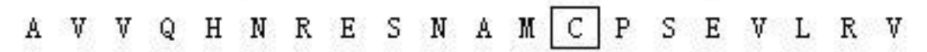 \\
\hline 241 & GTGAAGGCCAGGAGACAGTTGGTTGCTGGCTACAATTACGTCATAAOCAOCAAGATGATC \\
\hline 64 & 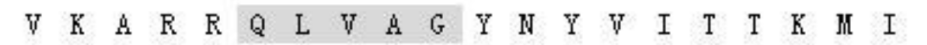 \\
\hline 301 & AGGACCGCCTGCAGAGGAACCGGTGAAAMTGCACCTTACGAGTGTGAATTCAAAGTGTGG \\
\hline 84 & 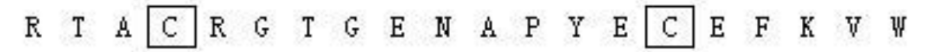 \\
\hline 361 & AGCCGCCCATGGCTGAHTGAAATATCGGTGACG TCAGTGAHATGCTAGaag agaact ac \\
\hline 104 & 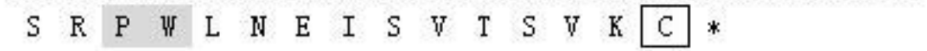 \\
\hline 421 & gtgggacctct cagtgttcacctgcatag agagt aat atgtaatt acctgtagatgaaa \\
\hline 481 & cacaaaagtattgcgtttctatttct gcctatgct act cactgtagtccat actagacc \\
\hline 541 & ttgaagtgtggttcagatttttaaattttaaactttttaatgcat agccactgaaacaca \\
\hline 601 & cctat aacaagt aattgtgt actgaattagcctactaaaaccatgcacttgtttaaaa \\
\hline 661 & tgaaattaaagtagcttgtgcactttaaaaaaaaaaa \\
\hline
\end{tabular}

Figure 1. Nucleotide sequence of cDNA and predicted amino acid sequences of the spinyhead croaker Collichthys lucidus cystatin C (Clcys). The deduced amino acid sequences are translated. Signal peptide sequences are bolded, Gly25, Q69LVAG73, P106W107, are shadowed, and four cys residues are boxed. The start codon (ATG) and stop codon (TGA) are bolded and underlined.

\section{Sequence analysis}

Forty-three amino acid sequences were obtained using "cystatins A, B, C, D, F" and "kininogen" as the key word when searching in the protein database (http://www.ncbi.nlm.nih. gov/guide/proteins/\#databases). All sequences were aligned by the ClustalW in MEGA 5.0 and a UPGMA tree was constructed using the MEGA software version 5.0. The confidence level in the generated tree was obtained using 1000 bootstraps. According to the tree, all cystatins were split between three branches (type I, type II, and type III), Clcys belongs to the type II of cystatin family, and is clustered with cystatin C of P. crocea (XP_010728274.1), Paralichthys olivaceus (ACC86115.1), and Danio rerio (NP_001026843.2) (Figure 2). Among the cystatins, all those from mammals were clustered, as were those from fish. Clcys is most closely related to $P$. crocea, thus supporting traditional taxonomic relationships. 


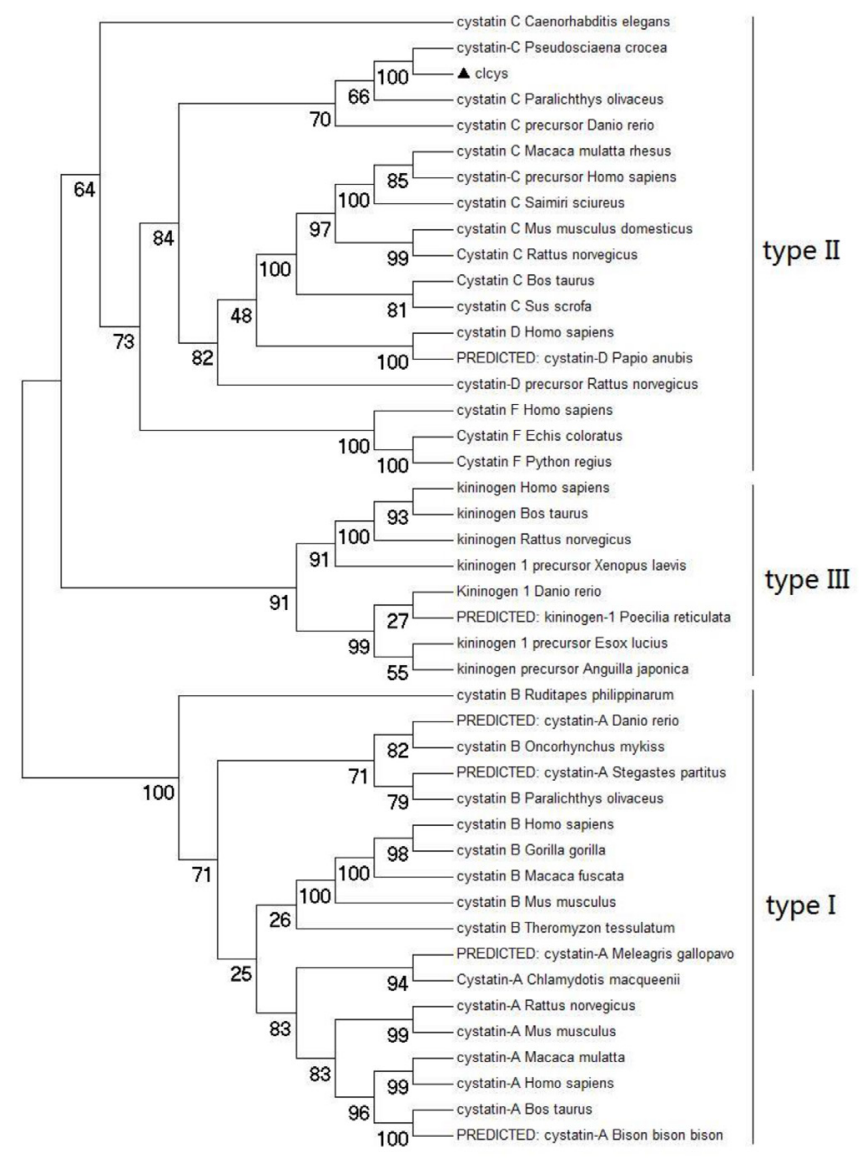

Figure 2. Evolutionary tree of Collichthys lucidus cystatin C (Clcys). The UPGMA tree is constructed using the MEGA 5.1 program based on multiple-sequence alignment by Clustal $W$. The scale bar corresponds to estimated amino acid substitutions per site. The protein sequences used in this analysis were obtained from GenBank as follows: cystatin-A Macaca mulatta (NP_001245071.1), cystatin-A Homo sapiens (NP_005204.1), cystatin-A Rattus norvegicus (NP_001099346.1), cystatin-ABos taurus (NP_001161296.1), PREDICTED: cystatin-ABison bison (XP_010832555.1), cystatin-A Mus musculus (NP_001028411.1), PREDICTED: cystatin-A Danio rerio (XP_698401.1), PREDICTED: cystatin-A Stegastes partitus (XP_008295700.1), PREDICTED: cystatin-A Meleagris gallopavo (XP_003202689.1), cystatin-A Chlamydotis macqueenii (KFP39525.1), cystatin B Homo sapiens (AAF44059.1), cystatin B Mus musculus (AAC52851.1), cystatin B Paralichthys olivaceus (ACC86114.1), cystatin B Theromyzon tessulatum (AAN28679.1), cystatin B Ruditapes philippinarum (AFP50149.1), cystatin B Macaca fuscata (BAC21008.1), cystatin B Gorilla gorilla (BAC20307.1), cystatin C Mus musculus (AAA63298.1), cystatin C Rattus norvegicus (AAH87591.1), cystatin C Bos taurus (AAl09630.1), cystatin C Saimiri sciureus (AAB64051.1), cystatin C Macaca mulatta (AAB49517.1), cystatin C Sus scrofa (ABG48755.1), cystatin C Caenorhabditis elegans (CAC33822.1), cystatin D Homo sapiens (CAA49838.1), cystatin-D precursor Rattus norvegicus (NP_001102431.1), PREDICTED: cystatin-D Papio anubis (XP_009214933.1), cystatin F Homo sapiens (CAD52872.1), cystatin F Echis coloratus (JAC96569.1), cystatin F Python regius (JAC94922.1), cystatin C precursor Danio rerio (NP_001026843.2), cystatin-C precursor Homo sapiens (NP_000090.1), kininogen Homo sapiens (AAB59551.1), kininogen Rattus norvegicus (AAA41486.1), kininogen Bos taurus (CAA24736.1), kininogen 1 precursor Xenopus laevis (NP_001088128.1), PREDICTED: cystatin-C Pseudosciaena crocea (XP_010728274.1), cystatin C Paralichthys olivaceus (ACC86115.1), kininogen 1 Danio rerio (AAH83429.1), kininogen 1 precursor Esox lucius (NP_001290822.1), kininogen precursor Anguilla japonica (AHV79431.1), PREDICTED: kininogen-1 Poecilia reticulata (XP_008404505.1). 
Eleven cystatin $\mathrm{C}$ amino acid sequences including Clcys were aligned by ClustalW in MEGA 5.0 (Figure 3). The results revealed that the typical features of Family 2 (G25, Q69LVAG73, and P106W107 in Clcys) were conserved. Among these sequences, Clcys had the highest identity with $P$. crocea (89\%), followed by D. rerio (40\%), P. olivaceus (38\%), and Homo sapiens $(35 \%)$. Interestingly, cystatin $\mathrm{C}$ sequences were relatively conserved among all mammal species under investigation, with the lowest identity of $68 \%$ found between $H$. sapiens and Rattus norvegicus. Two hypotheses can explain this; first, cystatin $\mathrm{C}$ may not be as conserved in fish species as it is in mammals, and second, the classification of cystatin $C$ in fish might differ from that in mammals. Considering that Clcys has high identity with $P$. crocea, which has a closely genetic relationship with C. lucidus (Qu et al., 2012), we tend to support the second hypothesis, although more cystatin $\mathrm{C}$ sequences need to be identified from fish species to confirm this hypothesis.

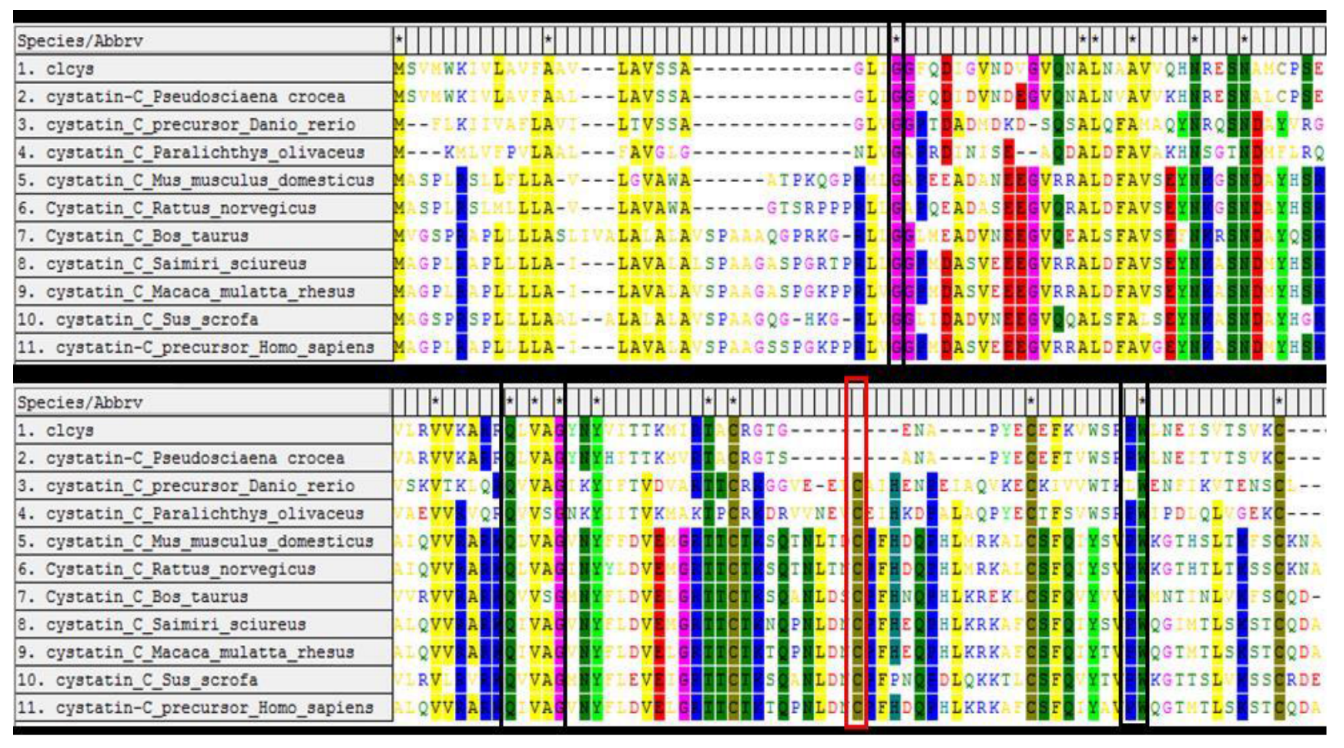

Figure 3. ClustalW alignment and comparison of the amino acid sequences deduced from Collichtys lucidus cystatin C cDNA with similar protein sequences of cystatins. Similarities more than $60 \%$ are labeled in different colors. The amino acid sequence deduced from spinyhead croaker is marked as Clcys. The typical feature of type II cystatins are in a black box, the deleted cys residue are in a red box. Other similar proteins are predicted and obtained from GenBank as follows: PREDICTED: cystatin-C Pseudosciaena crocea (XP_010728274.1), cystatin C Paralichthys olivaceus (ACC86115.1), cystatin C precursor Danio rerio (NP_001026843.2), cystatin C Mus musculus (AAA63298.1), cystatin C Rattus norvegicus (AAH87591.1), cystatin C Bos taurus (AAI09630.1), cystatin C Saimiri sciureus (AAB64051.1), cystatin C Macaca mulatta (AAB49517.1), cystatin C Sus scrofa (ABG48755.1), cystatin-C precursor Homo sapiens (NP_000090.1).

\section{Analysis of Clcys expression in various tissues}

The expression of Clcys in 10 tissues from adult $C$. lucidus was examined using qRTPCR. Clcys expression was found in all tissues, with the highest expression detected in the kidney, followed by the liver, heart, and testis, and the weakest expression in muscle (Figure 4). Lyccys expression was high in the spleen, kidney, and liver of $P$. crocea. There was a significant upregulation of Lyccys transcript in the spleen and kidney in response to poly (I:C) or an inactivated 
trivalent bacterial vaccine, and mRNA levels of $L y c T N F-2$ and $L y c / L-10$ in these two tissues were also significantly up-regulated by rLyccys (Li et al., 2009), suggesting that Clcys may also play an important role in immune processes of $C$. lucidus. However, the cystatin $C$ gene in $P$. olivaceus seems to be of the housekeeping type, and the Paralichthys olivaceus cystatin $\mathrm{C}$ gene was ubiquitously expressed throughout healthy and LPS-stimulated individuals (Ahn et al., 2013a). The expression pattern of cystatin C as a "housekeeping" gene also appears in diverse species, including humans (Abrahamson et al., 1990), mice (Huh et al., 1995), dogs (Sekine and Poulik, 1982), chickens (Colella et al., 1991), and salmon (Yamashita and Konagaya, 1996). The differential expression of Clcys in various tissues suggests that it is not a housekeeping gene; however, whether there is another cystatin $\mathrm{C}$ gene that serves as a housekeeping gene warrants further studied.

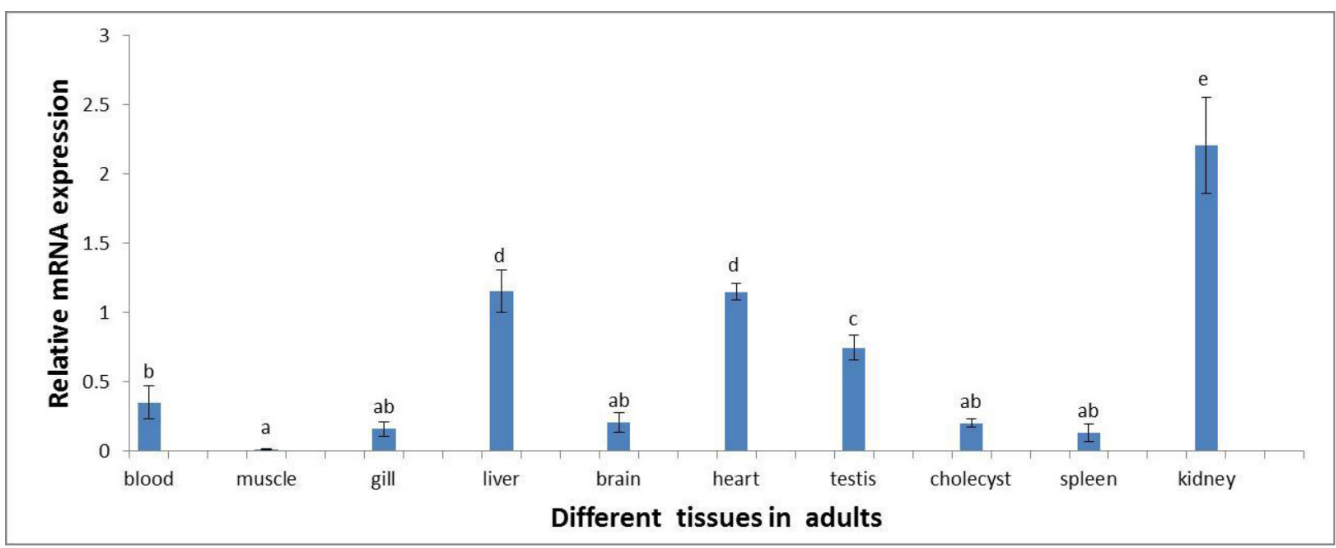

Figure 4. Expression profiles of Clcys in different tissues. Clcys mRNA was normalized to the 18S rRNA transcript level. Data are reported as means $\pm S D$ of three independently repeated experiments. The letter shows that there are significant differences during these stages $(P<0.05)$. The $y$-axis represents the relative ratio of expression levels of Clcys/18S rRNA mRNA.

\section{Conflicts of interest}

The authors declare no conflict of interest.

\section{ACKNOWLEDGMENTS}

Research supported by the Basic Research Fund for State-Level Nonprofit Research Institutes of ESCFRI, CAFS (\#Dong2015M08).

\section{REFERENCES}

Abrahamson M, Olafsson I, Palsdottir A, Ulvsbäck M, et al. (1990). Structure and expression of the human cystatin C gene. Biochem. J. 268: 287-294.http://dx.doi.org/10.1042/bj2680287

Ahn SJ, Bak HJ, Park JH, Lee JY, et al. (2013a). Olive flounder (Paralichthys olivaceus) cystatin C: cloning, mRNA expression, and enzymatic characterization of olive flounder cystatin C. Appl. Biochem. Biotechnol. 170: 1216-1228.http://dx.doi. org/10.1007/s12010-013-0248-5

Ahn SJ, Bak HJ, Park JH, Kim SA, et al. (2013b). Olive flounder (Paralichthys olivaceus) cystatin B: cloning, tissue distribution, expression and inhibitory profile of piscine cystatin B. Comp. Biochem. Physiol. B Biochem. Mol. Biol. 165: 211-218.http:/l dx.doi.org/10.1016/j.cbpb.2013.04.007 
Anastasi A, Brown MA, Kembhavi AA, Nicklin MJ, et al. (1983). Cystatin, a protein inhibitor of cysteine proteinases. Improved purification from egg white, characterization, and detection in chicken serum. Biochem. J. 211: 129-138.http://dx.doi. org/10.1042/bj2110129

Asnani M and Reid M (2015). Cystatin C: a useful marker of glomerulopathy in sickle cell disease? Blood Cells Mol. Dis. 54: 65-70.http://dx.doi.org/10.1016/j.bcmd.2014.07.018

Bai JJ, Lao HH, Ye X, Li Y-H, et al. (2002). Molecular cloning and sequence analysis of cystatin mature peptide cDNAs from two species of sturgeons. Acta Zool. Sin 48: 570-573.

Calero-Paniagua I, Ruíz-Chicote AM, Nieto-Rodríguez JA, Ruiz-Ribó MD, et al. (2014). [Usefulness of cystatin C as a prognostic marker in venous thromboembolism]. Med. Clin. 143: 530-534.http://dx.doi.org/10.1016/j.medcli.2013.08.007

Chang YS, Weng JW, Li CC and Huang FL (1998). Identification of cystatin as a component of carp chorion. Mol. Reprod. Dev. 51: 430-435.http://dx.doi.org/10.1002/(SICI)1098-2795(199812)51:4<430::AID-MRD10>3.0.CO:2-Z

Cheng J, Ma GQ, Miao ZQ, Shui BN, et al. (2012). Complete mitochondrial genome sequence of the spinyhead croaker Collichthys lucidus (Perciformes, Sciaenidae) with phylogenetic considerations. Mol. Biol. Rep. 39: 4249-4259.http:// dx.doi.org/10.1007/s11033-011-1211-6

Colella R, Johnson A and Bird JW (1991). Steady-state cystatin mRNA levels in chicken tissues in response to estrogen. Biomed. Biochim. Acta 50: 607-611.

Coll E, Botey A, Alvarez L, Poch E, et al. (2000). Serum cystatin C as a new marker for noninvasive estimation of glomerular filtration rate and as a marker for early renal impairment. Am. J. Kidney Dis. 36: 29-34.http://dx.doi.org/10.1053/ ajkd.2000.8237

Cornwall GA and Hsia N (2003). A new subgroup of the family 2 cystatins. Mol. Cell. Endocrinol. 200: 1-8.http://dx.doi. org/10.1016/S0303-7207(02)00408-2

Dharnidharka VR, Kwon C and Stevens G (2002). Serum cystatin C is superior to serum creatinine as a marker of kidney function: a meta-analysis. Am. J. Kidney Dis. 40: 221-226.http://dx.doi.org/10.1053/ajkd.2002.34487

Dieckmann T, Mitschang L, Hofmann M, Kos J, et al. (1993). The structures of native phosphorylated chicken cystatin and of a recombinant unphosphorylated variant in solution. J. Mol. Biol. 234: 1048-1059.http://dx.doi.org/10.1006/jmbi.1993.1658

Filler G, Bökenkamp A, Hofmann W, Le Bricon T, et al. (2005). Cystatin C as a marker of GFR--history, indications, and future research. Clin. Biochem. 38: 1-8.http://dx.doi.org/10.1016/j.clinbiochem.2004.09.025

Grubb A, Löfberg H and Barrett AJ (1984). The disulphide bridges of human cystatin C (g-trace) and chicken cystatin. FEBS Lett. 170: 370-374. http://dx.doi.org/10.1016/0014-5793(84)81346-0

Herget-Rosenthal S, Marggraf G, Hüsing J, Göring F, et al. (2004). Early detection of acute renal failure by serum cystatin C. Kidney Int. 66: 1115-1122.http://dx.doi.org/10.1111/j.1523-1755.2004.00861.x

Huh C, Nagle JW, Kozak CA, Abrahamson M, et al. (1995). Structural organization, expression and chromosomal mapping of the mouse cystatin-C-encoding gene (Cst3). Gene 152: 221-226.http://dx.doi.org/10.1016/0378-1119(94)00728-B

Jiang ST (2006). Effect of proteinases and their inhibitor, recombinant cystatin on the quality of surimi. J. Fish. Soc. Taiwan 33: 295-314.

Kang I and Lanier TC (2005). Inhibition of protease in intact fish fillets by soaking in or injection of recombinant soy cystatin or bovine plasma. J. Agric. Food Chem. 53: 9795-9799.http://dx.doi.org/10.1021/jf051231y

Li DK, Lin H and Kim SM (2007). Application of recombinant chum salmon cystatin to Alaska pollock (Theragra chalcogramma) surimi to prevent gel weakening. J. Food Sci. 72: C294-C299.http://dx.doi.org/10.1111/j.1750-3841.2007.00393.x

Li F, An H, Seymour TA, Bradford CS, et al. (1998). Molecular cloning, sequence analysis and expression distribution of rainbow trout (Oncorhynchus mykiss) cystatin C. Comp. Biochem. Physiol. B Biochem. Mol. Biol. 121: 135-143.http:// dx.doi.org/10.1016/S0305-0491(98)10074-3

Li S, Ao J and Chen X (2009). Molecular and functional characterization of a cystatin analogue in large yellow croaker (Pseudosciaena crocea). Mol. Immunol. 46: 1638-1646.http://dx.doi.org/10.1016/j.molimm.2009.02.027

Maher K, Jerič Kokelj B, Butinar M, Mikhaylov G, et al. (2014). A role for stefin B (cystatin B) in inflammation and endotoxemia. J. Biol. Chem. 289: 31736-31750.http://dx.doi.org/10.1074/jbc.M114.609396

Mohindra V, Tripathi RK, Singh A and Singh B (2013). Molecular characterization and expression analysis of a novel cystatinlike gene in a hypoxia-tolerant Indian catfish, Clarias batrachus [Linnaeus, 1758]. Fish Shellfish Immunol. 34: 683-687. http://dx.doi.org/10.1016/j.fsi.2012.11.018

Nakamura S, Ogawa M, Saito M and Nakai S (1998). Application of polymannosylated cystatin to surimi from roe-herring to prevent gel weakening. FEBS Lett. 427: 252-254.http://dx.doi.org/10.1016/S0014-5793(98)00437-2

Ni J, Abrahamson M, Zhang M, Fernandez MA, et al. (1997). Cystatin E is a novel human cysteine proteinase inhibitor with structural resemblance to family 2 cystatins. J. Biol. Chem. 272: 10853-10858.http://dx.doi.org/10.1074/jbc.272.16.10853

Ochieng J and Chaudhuri G (2010). Cystatin superfamily. J. Health Care Poor Underserved 21 (Suppl): 51-70.http://dx.doi. org/10.1353/hpu.0.0257 
Premachandra HKA, Whang I, Lee YD, Lee S, et al. (2012). Cystatin B homolog from rock bream Oplegnathus fasciatus: genomic characterization, transcriptional profiling and protease-inhibitory activity of recombinant protein. Comp. Biochem. Physiol. B Biochem. Mol. Biol. 163: 138-146.http://dx.doi.org/10.1016/j.cbpb.2012.05.012

Qu YJ, Liao R, Li JE and Gou XW (2012). Application of otolith morphology in species discrimination for Bahaba flavolabiata, Pseudosciaena crocea, Wak tingi and Collichthys lucidus. Guangdong Agric. Sci 39: 143-147.

Sadaf Z, Shahid PB and Bilqees B (2005). Isolation, characterization and kinetics of goat cystatins. Comp. Biochem. Physiol. B Biochem. Mol. Biol. 142: 361-368.http://dx.doi.org/10.1016/j.cbpb.2005.08.007

Sekine T and Poulik MD (1982). Post-gamma globulin : tissue distribution and physicochemical characteristics of dog postgamma globulin. Clin. Chim. Acta 120: 225-235.http://dx.doi.org/10.1016/0009-8981(82)90159-0

Su YC, Lin JC and Liu HL (2005). Homology model and molecular dynamics simulation of carp ovum cystatin. Biotechnol. Prog. 21: 1315-1320.http://dx.doi.org/10.1021/bp0501017

Vray B, Hartmann S and Hoebeke J (2002). Immunomodulatory properties of cystatins. Cell. Mol. Life Sci. 59: 1503-1512.http:// dx.doi.org/10.1007/s00018-002-8525-4

Wang SC and Huang FL (2002). Carp ovarian cystatin binds and agglutinates spermatozoa via electrostatic interaction. Biol. Reprod. 66: 1318-1327.http://dx.doi.org/10.1095/biolreprod66.5.1318

Xiao PP, Hu YH and Sun L (2010). Scophthalmus maximus cystatin B enhances head kidney macrophage-mediated bacterial killing. Dev. Comp. Immunol. 34: 1237-1241.http://dx.doi.org/10.1016/j.dci.2010.07.008

Yamada T, Ohta H, Shinohara A, Iwamatsu A, et al. (2000). A cysteine protease from maize isolated in a complex with cystatin. Plant Cell Physiol. 41: 185-191.http://dx.doi.org/10.1093/pcp/41.2.185

Yamashita M and Konagaya S (1996). Molecular cloning and gene expression of chum salmon cystatin. J. Biochem. 120: 483487.http://dx.doi.org/10.1093/oxfordjournals.jbchem.a021438

Zhao M, Song W, Ma CY and Zhang FY (2015). Population genetic structure of Collichthys lucidus based on the mitochondrial cytochrome oxidase subunit I sequence. J. Fish. Sci. China 22: 233-242. 